\title{
HIPNOSE, ICONICIDADE E DORES CRÔNICAS: CONSIDERAÇÕES CLÍNICAS
}

\author{
HYPNOSIS, ICONICITY AND CHRONIC PAIN: CLINICAL CONSIDERATIONS \\ HYPNOSIS, ICONICITY AND CHRONIC PAIN: CLINICAL CONSIDERATIONS
}

Maurício S. Neubern*

\begin{abstract}
RESUMO
Este trabalho busca oferecer, por meio da noção semiótica de iconicidade, uma proposta explicativa para a compreensão das relações entre hipnose e dores crônicas. Considera a hipnose como um conjunto de processos que envolvem a comunicação e a experiência de transe. Utilizando-se de breve vinheta clínica, destaca a iconicidade na comunicação hipnótica como processo fundamentado principalmente na consideração quanto ao outro, na clínica do mostrar e na vivência do presente. Por outro lado, na experiência de transe, destaca a iconicidade presente nas relações com a autoimagem e o esquema corporal do sujeito, que consistem em complexos sistemas semióticos nos quais as dores crônicas se configuram. Na conclusão do artigo, destaca-se a proximidade entre iconicidade e alteridade, sobretudo no que diz respeito ao papel do pertencimento dos protagonistas da relação terapêutica na hipnose.
\end{abstract}

Palavras-chave: Hipnose. Iconicidade. Dores crônicas. Complexidade. Semiótica.

\begin{abstract}
This work seeks to offer, by means of the semiotic concept of iconicity, an explanatory proposition in order to understand the relationship between hypnosis and chronic pain. It considers hypnosis as a set of processes involving communication and trance experience. Employing a brief clinical excerpt, it emphasizes iconicity in hypnotic communication, as a process based mainly on the consideration of the other, the clinic of showing and the experience of the present. On the other hand, regarding the trance experience, the work stresses the iconicity present in the relations with the self-image and the corporal scheme of the subject, consisting of complex semiotic systems in which the chronic pains are set. The conclusion highlights the proximity
\end{abstract}

\footnotetext{
Texto recebido em 22 de junho de 2018 e aprovado para publicação em 8 de agosto de 2019.

Este trabalho deriva do pós-doutorado do autor (estágio Sênior, CAPES 2015/2016) com o projeto: Hypnose, Complexité et Douleur Chronique, realizado no Centre Edgar Morin (CEM), École des Hautes Études en Sciences Sociales (EHESS), Paris, França. Agradecemos à CAPES pelo financiamento deste projeto.

* Professor adjunto na Universidade de Brasília (UnB). Endereço: Campus Darcy Ribeiro, ICC Sul, Instituto de Psicologia, Universidade de Brasília, Brasília-DF, Brasil. CEP: 70910-900. Telefone: (61) 3107-6890 ou (61) 99323-7007. E-mail: mauricio.neubern@gmail.com.
} 
between iconicity and alterity, especially with respect to the role of the protagonists of the therapeutic relationship in hypnosis.

Keywords: Hypnosis. Iconicity. Chronical pain. Complexity. Semiotics.

\section{RESUMEN}

Este trabajo busca ofrecer, por medio de la noción semiótica de iconicidad, una propuesta explicativa para la comprensión de las relaciones entre hipnosis y dolores crónicos. Se considera la hipnosis como un conjunto de procesos que involucran la comunicación y la experiencia de trance. Utilizando una breve viñeta clínica, se destaca la iconicidad en la comunicación hipnótica como un proceso fundamentado principalmente en la consideración en cuanto al otro, en la clínica del mostrar y en la vivencia del presente. Por otro lado, en la experiencia de trance, se destaca la iconicidad presente en las relaciones con la autoimagen y el esquema corporal del sujeto, que consisten en complejos sistemas semióticos en los cuales los dolores crónicos se configuran. En la conclusión del artículo, se destaca la proximidad entre iconicidad y alteridad, sobre todo en lo que se refiere al papel de la pertenencia de los protagonistas de la relación terapéutica en la hipnosis.

Palabras clave: Hipnosis. Iconicidad. Dolores crónicos. Complejidad. Semiótica.

\section{INTRODUÇÃO}

7 radicionalmente, as reflexões e pesquisas sobre hipnose procuram explicar os impactos dessa abordagem terapêutica tendo a técnica como foco central 1 (Jensen, \& Patterson, 2014; Zeig, 2014). A construção da sugestão, seus aspectos linguísticos e a aplicação de palavras e expressóes são destacados como os principais responsáveis pelos impactos da hipnose na experiência do sujeito com dores crônicas. Ao privilegiarem a técnica, tais perspectivas ressaltam um tópico de grande pertinência para a hipnose, pois destacam um aspecto que talvez seja específico dessa modalidade terapêutica (Roustang, 2015). É possível mesmo conceber que uma leitura que não implicasse a técnica em hipnose corresse o risco de desprezar uma dimensão central sua, que a caracteriza e a especifica clínica e historicamente.

As diversas perspectivas que discutem outros processos, como a relação terapêutica, parecem, contudo, padecer de outra ordem de dificuldades (Neubern, 2016). Ao mesmo tempo em que permanecem isoladas no pensamento de certos autores (Roustang, 2015; Zeig, 2014), não se mantendo em movimentos mais amplos de pesquisa, construção teórica e reflexão, nem sempre aprofundam 
questóes conceituais mais específicas, necessárias para o estabelecimento das relações entre clínica e pesquisa (Neubern, 2018). Malgrado a considerável pertinência clínica de tais propostas, a dimensão explicativa dos diferentes processos que ocorrem numa relação clínica de hipnose se torna repleta de lacunas: como se considerar, por exemplo, as palavras e gestos, e suas possíveis relações com os processos subjetivos, como seria a geração das emoções num setting de hipnose, como as sugestôes podem promover a construção do transe e aliviar as dores crônicas de um sujeito são exemplos de questôes que permanecem em aberto, sobretudo por conta da ausência de conceitos teóricos.

Nesse sentido, a perspectiva semiótica da iconicidade, isto é, a capacidade dos signos em transmitir as qualidades de um objeto (Jappy, 2013; Nöth, 2015), tem considerável potencial teórico para a compreensão clínica da hipnose, especialmente em suas relações com as dores crônicas. Entre suas diversas aplicaçôes (Hiraga, 2015), a iconicidade apresenta reflexôes pertinentes no tocante aos processos comunicacionais entre as pessoas, destacando a diversidade de signos que ali se apresentam e seus impactos na subjetividade destas, especialmente no que diz respeito aos processos de sentimento. Ela se articula a toda uma constelação de conceitos peirceanos (Peirce, 1998), com alto potencial explicativo para as duas dimensōes importantes que compõem a noção de hipnose (Neubern, 2016; 2017), ou seja, os processos relacionais e de influência, caracterizados, sobretudo, pela noção de sugestão, e as experiências de transe, que se caracterizam pelas diferentes alteraçôes das relações eu-mundo (espaço, tempo, matéria, causa, corpo e ser) e a consequente emergência de processos inconscientes com considerável potencialidade terapêutica.

Desse modo, o objetivo deste trabalho é o de propor uma leitura inicial, com base no conceito peirceano de iconicidade (Jappy, 2013; Nöth, 2015) para a compreensão das relações entre hipnose e dores crônicas. Para tanto, ele contará com uma sessão particular, explicitando os principais conceitos peirceanos articulados à iconicidade (como signo, semiótica e fenomenologia), e uma breve ilustração clínica, de um sujeito com dores crônicas em hipnoterapia, da qual serão destacadas algumas questóes sobre os processos relacionais e a experiência de transe. Ressalta-se, ainda, que, para a realização da pesquisa clínica, todos os cuidados éticos foram rigorosamente obedecidos, inclusive nas aprovações de comitês de ética institucionais e o sigilo da identidade do sujeito, por meio de nomes fictícios. 


\section{ICONICIDADE, SEMIÓTICA E FENOMENOLOGIA}

O termo iconicidade encontra suas origens na semiótica de Charles Peirce (apud Jappy, 2013), ou seja, o estudo dos signos (Peirce, 1998). Signo consiste naquilo que representa um objeto e também produz um efeito (interpretante) na mente de um interlocutor. Caso se considerem as relações com os objetos, os signos podem ser os ícones (de onde deriva o termo iconicidade), os índices e os símbolos. No caso dos primeiros, há uma relação qualitativa com os objetos, como no caso dos desenhos, hieróglifos, mas também verbos, advérbios e adjetivos; enquanto, no caso dos índices, essa relação é causal (as pegadas no chão ou os arranhões de um gato no móvel da casa), funcional (como as medidas de um termômetro). Em termos gramaticais, os pronomes e vocativos também funcionam como índices. Já os símbolos referem-se às palavras em geral, a leis, hábitos e convençôes, como os discursos e os livros.

Peirce (1998) também preconizou outro saber, a fenomenologia, que se refere a como experiência capta as coisas. A "primeiridade" é a dimensão dos sentimentos, do qualitativo, daquilo que ainda não existe, mas apenas é potencialidade e tem forte correspondência lógica com os ícones, ao passo que a "secundidade" refere-se ao reativo, ao que existe concretamente, ao fenômeno singular, aproximando-se logicamente dos índices. Por sua vez, a "terceiridade" consiste no campo do pensar, da organização, da lei e corresponde, em sua lógica, aos símbolos. Já iconicidade (Jappy, 2013; Santaella, 2009) também desdobra os ícones em outros três tipos de signos: os hipoícones, como as imagens (primeiraprimeiridade); os diagramas (segunda-primeiridade); e as metáforas (terceiraprimeiridade).

As imagens consistem em elementos de mera transmissão qualitativa, como um desenho ou uma figura imaginária, ao passo que os diagramas mostram relaçóes funcionais entre objetos, como os diagramas de livros científicos e as descrições de um acontecimento (Santaella, 2009). As metáforas, por outro lado, sintetizam, no mesmo signo, dois campos diferentes, como no exemplo popular "o amor é cego". Nessa figura de linguagem, a justaposição entre o campo dos sentimentos (amor) e o de uma deficiência física (cegueira) refere-se a uma situação na qual a pessoa parece perder o juízo racional ou o bom senso quando envolvida por tal sentimento. As metáforas têm uma variação (as alegorias) que não produzem essa justaposição nos signos em si, mas em seus interpretantes, o que pressupóe um conhecimento prévio dessas pessoas a quem chegam as mensagens sobre aquilo que é veiculado, mas não é diretamente apreensível. Tal é o caso das músicas de protesto em dados momentos históricos, dos signos de 
grupos determinados, como a maçonaria e a Igreja Católica, e ainda as fábulas de Esopo (Jappy, 2013).

Num processo hipnótico, mesmo que as sugestões possam ser concebidas isoladamente, concebe-se que a pesquisa clínica se torna viável quando são interpretadas como formas ou configuraçôes semióticas, uma vez que envolvem vários signos. Dito de outro modo, o processo envolve não apenas os gestos, expressões e palavras, mas o próprio papel que os protagonistas desenvolvem numa dada relação. A iconicidade reveste-se de grande importância nessa forma de pesquisa, principalmente por conta da perspectiva de uma clínica do mostrar (Neubern, 2016; 2017), ou seja, uma clínica na qual o foco não está no que é dito, mas no que é apresentado aos sujeitos, podendo gerar em seus mundos uma grande diversidade de processos semióticos. Logo, num dado contexto, com papéis específicos, a simples introdução de um tema e a forma de contá-lo podem implicar muitos processos de iconicidade com grande relevância terapêutica.

\section{ILUSTRAÇÃO CLÍNICA}

Marcus Vinícius, servidor público, 44 anos, buscou a hipnoterapia, aconselhado por um de seus médicos. Homem muito comunicativo, Marcus era divorciado, pai de dois filhos, tinha um considerável círculo social, inclusive ligado à Umbanda. Suas dores tiveram início havia três anos, após uma cirurgia estética (lipoaspiração), o que redundou numa situação desagradável com sua médica, que lhe negou inteiramente qualquer hipótese de dor relacionada à cirurgia. Alguns meses depois, um segundo médico lhe convenceu a realizar uma cirurgia de coluna, pois, segundo ele, as dores seriam originadas por uma instabilidade entre as vértebras da coluna. Para sua surpresa, após a cirurgia, as dores se agravaram, e mais medicamentos se tornaram necessários, de maneira que, ao ser procurado, seu segundo médico lhe afirmou que apenas realizava cirurgias, mas não tratava dores crônicas.

Marcus passou a viver uma série de problemas a partir de então. Ficou impossibilitado de trabalhar, tendo de recorrer frequentemente ao INSS e depender da ajuda financeira da família extensa. Seu círculo social se reduziu intensamente, uma vez que as dores o paralisavam e impediam de desempenhar atividades cotidianas simples, gerando muita incompreensão da parte de seus amigos e parentes: "As pessoas não acreditam em mim [. . . ] acham que estou inventando, pois não aguentam ficar ouvindo que essa dor não passa. Me dizem que seu eu tiver pensamento positivo, eu melhoro [. . .] elas não têm mais paciência comigo". Participou de alguns grupos no hospital de conversação e outro de hipnose, mas os considerou muito superficiais, inclusive por terem 
número definido de sessões. Não vendo mais retorno para suas atividades e planos, logo mergulhou em sério estado depressivo, passando a cogitar o suicídio como uma possível saída para seu problema.

Apesar de mergulhar em desespero, Marcus continuou a busca por ajuda profissional, encontrando uma médica de referência que passou a recebê-lo com certa frequência e ajudá-lo a administrar suas medicaçôes. Mesmo sem encontrar uma solução definitiva para seu problema, a médica, segundo Marcus, era prudente, respeitosa e o ajudava a pensar em possíveis caminhos para sua situação. Por suas indicações, acabou chegando a outros profissionais que, de forma muito discreta, aventaram o possível erro médico da primeira cirurgia, na qual a extração de gordura teria sido excessiva. No entanto, a partir desses encontros com a terceira médica, que foi aventada a possibilidade da hipnoterapia na clínica-escola da universidade, tanto como forma de atenção psicológica como recurso de alívio de suas dores. As sessóes foram semanais, em torno de 90 minutos cada, e duraram cerca de um ano. Ao fim do processo, Marcus havia desenvolvido importantes reconfigurações de sua experiência de dor, que se reduziram consideravelmente. Retomou grande parte de seu círculo social e pensava, junto a seu trabalho, numa possibilidade de recolocação profissional.

\section{ALÉM DAS TÉCNICAS}

\subsection{Iconicidade e relação terapêutica}

Além da técnica e suas implicações, existem processos relacionais que têm a mais alta relevância na clínica hipnótica (Roustang, 2015), principalmente no caso das dores crônicas. $\mathrm{O}$ caso de Marcus é bastante ilustrativo nesse sentido ao relatar suas experiências contraditórias com diferentes profissionais:

Marcus - A doutora Francisca (a primeira médica) simplesmente me ignora até hoje. E já faz quatro anos. Ela disse que meu problema deve ser por conta de outra coisa, que o procedimento dela não causaria isso. Eu digo que eu era saudável, nunca tinha tido isso até fazer essa cirurgia [. . .], e agora, ela não me recebe mais, nem meus telefonemas, me bloqueou no zap [. . .] Pôxa (em choros), eu achei que éramos amigos, eu já conhecia a família dela, tínhamos intimidade [. . .], e eu sou respeitoso [. . .], não ameacei, não xinguei, não tratei ela mal [...]. Doutor Antônio foi outro. Disse pra mim que ele só fazia cirurgia e não tratava dores crônicas. Mas por que me prometeu ficar bom? Ele me convenceu a fazer essa cirurgia de coluna. Disse que os mariners americanos fizeram essa cirurgia e, uma semana depois, já estavam fazendo exercício [. . . ]. Na hora de prometer, vale tudo, mas, na hora de ver como fiquei, vira as costas? Só a doutora Paula me ajudou mesmo. Ela não sabe muito o que fazer [. . . ] mas me ajuda a ponderar as coisas. Ela não desistiu de mim. Me recebe, conversa comigo, me escuta, me acompanha, me dá conselhos. E me ajuda muito, 
mesmo sem resolver meu problema. Eu posso confiar nela. Assim como eu posso confiar no senhor, professor. Eu venho aqui e converso e falo de coisas que eu não posso falar com mais ninguém. As pessoas não acreditam em mim. Então, elas se cansam e me criticam [...] ou me propõem umas coisas mágicas - "Se você tiver pensamento positivo, você consegue, meu filho", disse minha tia [. . .]. Eu só agradeço e não converso mais. Aqui não, a gente pode conversar, e você se interessa. E tem mais: a hipnose funciona mesmo. Se eu ficasse só conversando, eu talvez enrolasse o senhor. Mas, na hipnose, não tem jeito. Sou eu comigo mesmo. E melhora muito as minhas dores. Saio daqui muito bem. Demora muito pras crises voltarem.

O relato de Marcus promove um valioso ensinamento sobre as dores crônicas, nem sempre captado e compreendido pelos profissionais de saúde, inclusive aqueles que se utilizam da hipnose: mesmo quando a técnica falha, a consideração com o outro (que o acolhe, compreende e reconhece) constitui-se como uma poderosa influência para o processo relacional. Esse princípio, que escapa aos dois primeiros médicos, mas não à terceira, destaca como as dores crônicas exigem a consideração do humano como prioritária, não as reduzindo jamais a um único foco explicativo, como o corpo biológico. A maneira como as pessoas vivem, sentem, relacionam-se e se posicionam ante o mundo consiste num princípio clínico fundamental para a lida com as dores crônicas (Neubern, 2014). É certo que pessoas acometidas por dores crônicas, como Marcus, não costumam abrir mão das promessas técnicas que, num futuro próximo ou não, sejam capazes de eliminar ou, ao menos, aliviar suas dores. Também é correto afirmar que tais promessas têm limites éticos e técnicos, que precisam ser considerados e cuidadosamente avaliados sob a pena de implicarem novamente os sujeitos em escaladas de procedimentos cada vez mais arriscados, mas nem sempre eficazes. Contudo, para que essa promessa continue viva e mantenha o sujeito engajado em alguma forma de cuidado, a relação terapêutica necessita permanecer como uma espécie de solo de primeiridade, no qual o terapeuta se faça, sobretudo, presente junto ao outro (Neubern, 2016).

É precisamente nesse ponto que a relação entre iconicidade e hipnose se faz mais marcante. Por um lado, tal proposta relacional é hipnótica, uma vez que remete a uma dimensão intencional de influenciar o outro (Erickson, 1985; Roustang, 2015), de modo subliminar, uma proposta relacional específica que lhe visa a promover determinadas experiências que contemplem suas demandas clínicas, mobilizem seus recursos e sejam pertinentes com seu mundo de experiências. Assim, quando o terapeuta se coloca numa condição acolhedora e disponível a Marcus, ao mesmo tempo em que lhe veicula a ideia de que existe alguma possibilidade a ser descoberta para remediar seu problema, também lhe transmite um profundo reconhecimento sobre sua sofrida situação. Tal acolhimento é altamente perpassado pela primeiridade, na qual o presente vivido 
por ambos favorece uma perspectiva do possível e da criação para os temas ali tratados, o que parece ser fundado sob a influência do sentir que atravessa e perpassa ambos os protagonistas em processos muito além das deliberações do eu. Esse espaço do comum, do compartilhado, do presente e do qualitativo é intencionalmente criado como forma de influência que promoverá, de modo decisivo, a construção do contexto terapêutico.

Por outro lado, semelhante proposta é altamente perpassada pela iconicidade, especialmente na ótica do mostrar, que contempla as formas semióticas como um todo e suas transmissões qualitativas na relação terapêutica (Neubern, 2016). Nesse processo, os signos envolvidos referem-se a objetos pertinentes à demanda clínica, como o jaleco branco do médico (ao saber médico), o título de psicólogo (ao saber psicológico), o termo hipnose (a uma técnica mágica ou poderosa), sem contar toda uma gestualidade, frases e expressões de conhecimento que são decisivas para a formação da relação. Como formas semióticas que compõem o jogo relacional, constituem-se como papéis e atitudes que se aproximam, em larga medida, de ícones, transmitindo qualidades muito além da palavra, que se endereçam a níveis profundos e inconscientes, perpassados pelo sentir. Tais transmissóes, a bem dizer, mostradas ao sujeito, são decisivas para a proposta de lugar que é ofertado ao outro nessa relação, o que pode significar para ele "ser aceito e respeitado" (como no caso da terceira médica e do terapeuta), "ser traído" (como no caso da primeira médica) e "ser passado para trás" (como no caso do segundo médico).

Semelhantes considerações são de grande valia para a clínica das dores crônicas em geral e da hipnose em particular, uma vez que alertam para os riscos das relações entre técnica efetiva e problemas agudos (Polejack, Vaz, Gomes, \& Wichrowski, 2015). Há aqui não apenas o problema da frustração diante de quadros sem cura, mas também os riscos de os profissionais e serviços nada poderem oferecer ao outro (já que não conseguem obter resolução definitiva de suas dores) e, por conseguinte, abandoná-lo. Logo, a cronicidade dessas dores aponta para necessidades relacionais específicas que não deveriam ser menosprezadas nas propostas de tratamento e terapia, uma vez que ocupam um papel central no universo de experiências das pessoas que as vivenciam cotidianamente (Breton, 2010).

É assim que a hipnose, como processo perpassado pela iconicidade (Neubern, 2016; 2018), destaca sobretudo a importância do "estar presente" junto ao outro, o que se desdobra basicamente em três princípios relevantes quanto ao universo das dores crônicas. Primeiramente, o estar presente implica a construção de um "nós" no processo relacional, no qual o terapeuta nada sabe, a princípio, sobre o 
outro, mas somente o pode compreender a partir de uma relação de vínculo com ele. Trata-se da concepção dos significados próprios e singulares do sujeito, que não devem ser abafados pela imposição teórica do terapeuta (Roustang, 2015), mas compreendidos no universo de experiência daquele sujeito, que só pode ser acessado por meio de uma relação afetiva de confiança e um interesse genuíno por ele. Não é apenas o saber científico, encarnado no médico ou psicólogo, o que importa: é fundamental o interesse pelo mundo do outro, sobre como suas dores o afetam e, mais que isso, sobre quem é essa pessoa, como é seu cotidiano, suas relaçóes, seu trabalho, suas crenças e projetos de vida.

Uma das primeiras consequências de tal atitude é o deslocamento da compreensão da dor como um fenômeno puramente biológico para um fenômeno complexo que envolve uma diversidade de dimensôes (econômicas, sociais, culturais, políticas, espirituais, familiares). Logo, ao poder trazer para semelhante espaço relacional questões relativas à sua situação de trabalho, seu isolamento social, seus dilemas nas instituições de saúde, suas crises financeiras, suas crenças religiosas e seus papéis na família (Breton, 2010), o sujeito tende a ampliar seu foco de compreensão sobre sua condição de vida, ao mesmo tempo em que pode se sentir reconhecido em sua humanidade naquele contexto. Em suma, em vez de ser apenas o paciente com uma dor específica (originária de problemas como fibromialgia, oncologia, anemia falciforme e lesão cirúrgica), ele é situado na relação como um sujeito, como no caso de Marcus, que é acometido por lesão cirúrgica e também é divorciado, pai de dois filhos, servidor público, umbandista e tem problemas econômicos para pagar seu tratamento. Não se limitando a mero levantamento de informações, essa ampliação de foco muda radicalmente a perspectiva do tratamento, podendo oferecer alternativas relevantes de mudança (Bioy, 2018; Neubern, 2014).

Em segundo lugar, a proposta do estar presente traz uma dimensão temporal da mais alta importância para a clínica das dores crônicas. Isso porque, ao estar presente com o outro, focado no agora, o mostrar atua como um poderoso desvio de foco: mergulha-se numa dimensão de primeiridade altamente permeada pelo que ainda não existe, que ainda é inefável e não está concretamente definido, ou seja, o que ainda é potencial (Nöth, 2015). Essa dimensão qualitativa e diáfana não tem, a princípio, poder de ação capaz de alterar um problema concreto, como uma lesão cirúrgica, mas atua com grande capacidade de influência sobre as dimensões do sentir, centrais na subjetividade (Schore, 2016). Se a lesão em si não pode ser influenciada, a vitalidade, as sensações, as percepções, os significados e sentidos, assim como emoçóes e sentimentos o podem, o que confere novas perspectivas de tratamento. Assim, essa experiência do novo pode transformar as configurações de uma dor de algo impermeável a suas ações para algo passível 
de influência, principalmente por conta dos novos processos qualitativos ali implicados.

Outro ponto digno de nota refere-se à temporalidade envolvida na experiência de dor, comumente enrijecida num foco no passado e sem muitas ou quaisquer perspectivas de futuro (Erickson, 1985; Neubern, 2014). A possibilidade de deslocamento para o presente consiste numa via de grande relevância clínica para a flexibilização de tal enrijecimento, principalmente quando esse processo é acompanhado pelo alívio da dor, seja pelo transe formal, seja pelo desvio de foco. Ao mesmo tempo, a revisão histórica que tais movimentos temporais proporcionam consiste em importante recurso terapêutico, posto que novas configuraçôes e propostas narrativas podem ser criadas sobre o sujeito, sua história e seus destinos, e a própria ocorrência da dor ser concebida sob novos símbolos. Não raro, quando a reconfiguração das dores promove narrativas que envolvem uma ótica de possibilidade e não de fatalismo, há a criação de importantes alternativas de sentido para as dores, como no caso das pessoas que já participaram da prática clínica do autor, que as nomearam como "professora rude", "provação divina", "pagamento de vidas passadas", "chance de repensar a vida", "convite doloroso para mudar de vida".

Em terceiro lugar, encontra-se o espaço que o terapeuta ocupa no mundo de experiências do sujeito. $\mathrm{O}$ contrato relacional estabelecido, que reconhece o sujeito em sua humanidade e o situa numa postura protagonista, tende a se constituir como uma forma semiótica, da qual emerge um interpretante de grande pertinência clínica: a figura do terapeuta (Melchior, 1998). Ao ser subjetivado pelo sujeito, ele passa a ocupar um lugar-chave no processo terapêutico, o que costuma ter desdobramentos de considerável relevância. Sua imagem e voz podem emergir durante os transes, inclusive de auto-hipnose, conduzindo-o a espaços protegidos e confortáveis e aliviando suas dores. Podem também brotar em sua mente, em momentos críticos de seu cotidiano, na qual os processos vivenciados em terapia parecem emergir e oferecer novos recursos narrativos e imaginários para determinados problemas. Até mesmo nos sonhos ou experiências religiosas, tais produçôes semióticas podem desempenhar um papel importante, compondo novas configurações da mais alta relevância clínica para suas demandas e dilemas.

Desse modo, a perspectiva do sujeito de, a bem dizer, levar o terapeuta consigo em seu mundo (Zeig, 2014) tem considerável importância na clínica das dores crônicas, particularmente devido às influências nada desprezíveis de problemas como a depressão e os pensamentos suicidas. A figura externa do terapeuta transforma-se num interpretante, mas também numa espécie de signo interno (Colapietro, 1989) que se liga ao anterior, embora tenha uma subjetivação típica 
do mundo interno. Isso porque, quando o terapeuta se torna esse signo no mundo do outro, que acompanha e cuida dele, passa a ocupar uma paisagem de seu imaginário, por vezes comprometida com uma negatividade densa que invade e paralisa suas perspectivas de pensar, agir e sentir (Minkowski, 2005). Conforme se constitui nesse mundo, rompe com a hegemonia dessa rede de ideias negativas, tornando-se uma espécie de agente interno de reconstrução de semelhante panorama subjetivo. Pode consistir também num passo inicial para a ruptura do isolamento afetivo que se impõe, comumente, a tais sujeitos. Isso porque um ícone que se instale nesse mundo interno e imaginário tende a evocar outras qualidades de sentimentos marginalizadas pelas configurações negativas e, ao mesmo tempo, a estabelecer vínculos mais consistentes com as oportunidades de mudança que surgirem no mundo concreto.

\subsection{Iconicidade e transe}

Uma vez que a relação terapêutica se mantém numa fundamentação qualitativa favorável, como acima mencionado, a dimensão técnica, sobretudo no que concerne ao transe, pode atingir níveis de influência e transformações profundas. Além do saber que envolve a construção da técnica hipnótica (Erickson, 1985), o próprio imaginário em torno do tema, em muito perpassado pelo mágico e pelo extraordinário (Bioy, 2018), somam-se ao solo afetivo de confiança da relação, colocando o sujeito num papel mais receptivo às influências e protagonistas do processo terapêutico. Semelhante mistura entre relação afetiva e aplicação técnica resulta numa dimensão de eficácia diferenciada, não apenas pelos efeitos, por vezes, imediatos e impactantes, mas principalmente pela apropriação que o sujeito pode desenvolver das mudanças promovidas pelo transe, mantendo-as na vida cotidiana (Neubern, 2014). Cabe, nesse ponto, uma leitura dialógica (Morin, 2005) na qual, se a relação é fundamental para que a técnica ganhe vida e influencie profunda e duradouramente o sujeito, a técnica também é de grande importância para que a confiança se estabeleça e a relação se solidifique, principalmente quando se mostra eficaz quanto a um problema terrível e persistente como as dores crônicas.

Há aqui uma hipótese de grande pertinência sobre os possíveis impactos da iconicidade durante o transe (Neubern, 2017). Considera-se que, nesse estado, as alterações de referência eu-mundo permitam uma flexibilização considerável entre a experiência interna e o mundo concreto de sujeito (Colapietro, 1989). Tais alterações podem levar o eu a experimentar dimensões de tempo, espaço e materialidade distintas, de maneira que a simples lembrança de uma experiência passada em transe (como um mergulho no rio) faça com que o sujeito se 
transporte para lá em seu imaginário e o vivencie de modo bem concreto, sendo envolvido intensamente nas diversas sensações e sentimentos ali presentes. $\mathrm{O}$ tipo de consequência que tais processos favorecem parece ser de grande relevância e pode ser pensado, basicamente, em dois níveis.

O primeiro deles se refere a um sistema de experiências conhecido como esquema corporal (Gallagher, \& Zahavi, 2008), que envolve um conjunto de processos de postura, sensações e movimentos. A passagem a seguir é ilustrativa nesse sentido:

E você pode, Marcus, perceber o que ocorre quando está em transe [. . .], essa sua mão que se coloca sobre seu abdômen [. . .], e você pode senti-la [. . . e perceber o que ela transmite a seu corpo [. . .], e algumas coisas você pode perceber de alguma forma [. . .] e outras não [. . .], e um certo calor [ . . ] talvez algum formigamento ou vibração [ . . ], talvez cores [. . .], imagens [. . .], choques parecidos a eletricidade [. . .], enquanto sua mão repousa em seu abdômen [. . .] e enquanto sua respiração segue serena, seu corpo está repousado, seus pés suspensos no ar, seu corpo parece se confundir com a poltrona [. . .], porque há muitos outros processos que influenciam seu corpo intensamente e seu consciente não sabe.

Após o transe, Marcus comentou:

Professor, senti algo engraçado durante o transe. Senti uma espécie de eletricidade, alguns momentos de choque, e isso me aliviava muito [. . .], um calor [. . .], mas teve uma hora que aconteceu um negócio engraçado. Aquele músculo interno, ele parece travado, para proteger o corpo ele trava, daí que vem a dor. Então, durante o transe, eu senti ele se soltar, parecia uma corda forte soltando em partes tá-tá-tá [. . .], aí ele relaxava e eu senti um alívio incrível.

A primeira passagem acima destaca uma sequência de sentenças óbvias (truísmos) que descrevem experiências particulares e evidentes para o sujeito (Zeig, 2014). Esse conjunto, a bem dizer, descritivo, funciona como um diagrama muito voltado para suas vivências corporais, pois parece refleti-las como num espelho. Dois pontos aqui merecem atenção. Esse diagrama apresenta, por um lado, um aspecto subliminar, em que o terapeuta parece adentrar seu mundo imaginário, com sua voz e imagem, e descrevê-lo para o sujeito. Tudo se passa como se ele exercesse ali algo próximo de uma leitura de pensamento (Melchior, 1998) e, mais que isso, como se estivesse presente ali naquele mundo e pudesse tocá-lo e influenciá-lo diretamente (Neubern, 2016), o que confere uma influência particular no esquema corporal e, consequentemente, no alívio das dores crônicas ali configuradas.

Por outro lado, tal espelhamento, em que consiste o diagrama, não é numa cópia fiel de sua realidade, mas numa cópia que apresenta pertinência com relação 
a sua produção semiótica e, ao mesmo tempo, é intencionalmente organizada sob um foco terapêutico. No caso específico acima, os truísmos são associados a sentenças que incluem possibilidades de sensação (calor, formigamentos, choques, vibrações) que proporcionam não apenas uma associação com sensações de alívio, mas também uma perspectiva de alteração das configurações semióticas daquele esquema corporal. Mais que isso, a sentença situada ao fim dessa sequência prenuncia a ação de recursos terapêuticos além da consciência. Assim, dadas as próprias características do transe (Neubern, 2018), inclusive dessa entrada do terapeuta no mundo interno do sujeito, o diagrama não se limita a espelhar o que lá já existe, mas favorece também a evocação de tais processos, situando-os sob um enquadre terapêutico específico. Esse processo é de grande relevância no caso de tais pessoas que, muitas vezes, já se sentem impotentes, desnorteadas e esgotadas quanto ao que fazer conscientemente para lidar com suas dores crônicas.

No trecho acima descrito, o relato de Marcus é de grande relevância em termos da produção semiótica que acompanha o processo hipnótico. Ele não somente faz alusão aos termos usados nas sugestões (como choque, calor e eletricidade), mas, principalmente, destaca um fenômeno inesperado, na qual a musculatura se solta em movimentos gradativos e bruscos até atingir certo relaxamento e lhe proporcionar um grande alívio de suas dores. Em outras palavras, esse algo inesperado e além de seus recursos conscientes, como anunciado na sugestão, que ele tanto almejava por se constituir como sua necessidade principal, aparece ali como fruto da influência desses processos além de seu pensamento consciente.

O segundo nível afetado pela iconicidade refere-se à autoimagem, um complexo sistema identitário que toma o corpo como um de seus principais integrantes (Gallagher, \& Zahavi, 2008). Trata-se de um sistema de produções subjetivas sobre si, envolvendo como o sujeito simboliza signos autorreferenciais e se posiciona em suas relações no mundo a partir deles. Voltando-se ao caso clínico, o seguinte trecho da fala do terapeuta é digno de atenção:

E quando você segue esse rio, sabe que ele busca algo, mesmo que ele não tenha uma consciência. Ele brota, entre pedras e paus, no seio da terra [.. .], esbarra aqui e ali com mais pedras, plantas [.. .] acidentes do relevo [...] e desvia [...], deixa-se encher para superar um tronco [...], cai em buracos [.. .] e se enche novamente [...], sempre seguindo seu caminho até virar um córrego [. . .], e deve ser muito bom poder ser ele, esquecendo-se de tudo e simplesmente seguindo adiante. Apenas sendo esse rio [. . .], sentindo-se água e fluindo pra frente [...], encontrando outros rios [...] e chegando ao mar [...], e me pergunto por que certas pessoas têm encontros estranhos durante o transe. Com pessoas ou seres que nem conhecem, mas dizem coisas importantes [. . . ] chegam perto desse alguém e recebem algo que pode levá-las a pensar por muito tempo [. . . coisas estranhas do transe. 


\section{E, logo após o transe, Marcus acrescenta:}

Professor, eu encontrei uma pessoa dessas. Era uma mulher. Era bonita e parecia ser alguém da luz. Eu estava nadando no rio [.. .], sendo levado por ele, e vi uma ilha. Quando cheguei perto, essa mulher apareceu e me disse: 'Marcus, precisa ser sempre do seu jeito?'. Eu ri meio sem graça, porque sei do que ela tava falando. Eu sempre quero as coisas do meu jeito.

De fato, é possível considerar que, nesse momento da terapia, Marcus se apresentava como alguém destruído pela dor, um homem que repensava se valeria a pena ou não viver e que não via um futuro pela frente. A evocação da imagem de um rio se tornou, para ele, pertinente por duas razóes principais. Primeiramente, o rio é algo que flui sem esforço por entre inúmeros obstáculos, até chegar a seus "objetivos", como o encontro com outros rios, um lago ou até o mar. Aqui parece haver algumas mensagens importantes: ele flui entre obstáculos (e Marcus está paralisado), tem objetivos que não conhece (e esse pode ser o caso do sujeito) e acaba, sem esforço, chegando a eles (o que talvez ele possa também descobrir como fazer). Dá ainda, contudo, outro ponto de grande relevância: para que se descubram tais potencialidades escondidas em si, a sugestão pede que ele se identifique com o rio, a ponto de se esquecer de tudo o mais, ou seja, mergulhando numa espécie de amnésia quanto a preocupaçôes cotidianas do eu. Assim, ele pode encontrar essa direção imposta pela natureza, muito ligada na imagem ao sentir, e seguir um caminho possível para seu destino. Trata-se de um uso da amnésia muito importante nos trabalhos com dores crônicas (Erickson, 1985).

Já o segundo ponto refere-se ao recado que a misteriosa mulher lhe transmite durante o transe. Marcus, algumas vezes, culpava-se por ter buscado cirurgias por vaidade, buscando um caminho mais fácil para melhorar sua aparência. Considerava-se como alguém sempre no controle, capaz de dominar sua vida e decidir os caminhos a tomar, o que era altamente impossibilitado pelas dores crônicas. $\mathrm{O}$ aspecto imaginário do transe trouxe, nesse sentido, uma mensagem clara a qual ele compreendeu rapidamente: as coisas não precisariam ser sempre feitas segundo seu controle. Talvez precisasse aprender a deixar a vida fluir melhor, como era o caso daquele rio. No entanto, aqui há um detalhe muito importante: a figura de uma mulher que surge inesperadamente. As mulheres, na vida de Marcus, comumente eram figuras sob seu domínio, com as quais ele nem sempre havia se portado de modo ético. Assim, o surgimento, tanto por ser inesperado como por ser de uma figura feminina, colocava em questão sua atitude de controle com relação ao mundo, que havia falido por conta das dores crônicas, mas que poderia ser revisto, caso ele aprendesse a se comportar como aquele rio. De certo modo, essa imagem, como um todo, acabou funcionando 
como uma alegoria (Jappy, 2013), uma vez que veiculou, numa dimensão profunda de sua interpretação, diferentes campos relevantes de sua vida, como a relação com as mulheres e sua atitude controladora quanto aos temas da vida.

\section{CONSIDERAÇÕES FINAIS}

Casos como o de Marcus trazem uma aproximação de grande pertinência entre duas noções muito importantes para a clínica da hipnose (iconicidade e alteridade), como pode ser ilustrado na citação a seguir (Landes, 1970, apud Segato, 2005, p. 7):

Viajando entre os povos do mundo, é possível perceber que as personalidades daqui lembram as personalidades de lá, por baixo e apesar das diferenças culturais. Portanto, uma e outra vez, volta-se à casa de amigos e parentes. Por trás das variaçōes culturais, não somos todos iguais, mas somos reconhecíveis. Quando o pesquisador de campo reconhece as personalidades dessa forma na cultura alheia, ele descobre a sua própria.

A ideia segundo a qual os outros se tornam reconhecíveis, a partir desse retorno à casa de amigos e parentes diz respeito, por um lado, ao retorno ao próprio ethos do terapeuta, isto é, seus nichos culturais e existenciais de pertencimento (Neubern, 2017). Trata-se do poder hipnótico da experiência do outro, inclusive de sua dor e sofrimento, que faz com que o terapeuta revisite seu próprio mundo e se permita sensibilizar em seus sentimentos mais profundos, uma vez que o sofrimento tem a capacidade de situar os humanos em um solo comum de impotência e finitude, a despeito de suas variadas diferenças. Por outro lado, essa dimensão ética da clínica hipnótica pode ser concebida também como um "co-mover-se" (Neubern, 2016), pois, a partir de seu próprio mundo que se comove com a dor do outro, o terapeuta se dirige a ele, fazendo com que a terapia se constitua como um encontro de mundos, no qual o sujeito e aqueles que habitam seu universo são também reconhecíveis com base nos amigos e parentes do próprio terapeuta.

Longe de se constituir como uma armadilha transferencial, tal atitude remete a uma noção de consciência (Colapietro, 1989) na qual o terapeuta se observa e se responsabiliza por aquilo que oferece ao outro, a partir do que já viveu e experimentou junto aos seus. A iconicidade, portanto, está nesse oferecimento de si ao sujeito e aos seus que, de alguma forma, reverberam em seu próprio mundo, evocando no terapeuta as presenças importantes que nele habitam. Se a prudência técnica demanda atenção para que não fuja a seu papel de terapeuta, essa relação perpassada pela iconicidade lhe favorece entrever nesse outro sua mãe, seu pai, seus irmãos, tios, filhos, avós, primos e amigos, o que proporciona 
a construção de um solo fundamental calcado no sentir para a clínica das dores crônicas. Sem uma fundamentação relacional dessa natureza, as relações terapêuticas tendem a se inviabilizar, principalmente em situaçóes crônicas, como a de Marcus, nas quais os procedimentos técnicos, por longo tempo, não trouxeram respostas satisfatórias, suas dores não receberam tratamento eficaz, as explicações médicas e psicológicas não eram consistentes e o suicídio se afigurava como única solução.

Tal concepção calcada na subjetividade, ou, numa palavra, na humanidade, das dores crônicas não as restringe a uma situação de polarização entre o frio olhar médico, geralmente tecnicista, e uma questão de direito (Polejack et al., 2015), por vezes negligenciada nessas situaçôes. Trata-se de conceber que a dor se articula em diferentes níveis de produção semiótica (Neubern, 2016) da experiência do sujeito, sendo particularmente habitada por processos pessoais, sociais, culturais, econômicos, religiosos, trabalhistas, familiares e espirituais (Breton, 2010). O processo hipnótico, assim como os serviços voltados para dores crônicas em geral, não deve se limitar a índices que podem apontar eventualmente para determinadas síndromes, mas considerar as diferentes articulações nas quais as dores se configuram e que são fundamentais, em sua pertinência, ao mundo desse sujeito. Mais que isso, devem considerar que o paciente não é um corpo inerte a ser manipulado de fora por um especialista, mas um sujeito pensante, inserido histórica, cultural e biologicamente numa sociedade, o que demanda que o tratamento se constitua também como uma forma de convivência (Neubern, 2014). Sem essas condiçóes, as diversas lacunas deixadas pelos insucessos técnicos podem conduzir o sujeito a um caminho incapaz de gerar alternativas, levando-o a uma profunda sensação de abandono, revolta e impotência. Caso a médica e o terapeuta não buscassem construir com Marcus esse solo relacional, com novas narrativas e potencialidades técnicas, seu suicídio seria um caminho provável, principalmente por conta dos diversos insucessos consequentes a procedimentos meramente técnicos.

Nesse sentido, é possível conceber que a iconicidade evoca no terapeuta uma responsabilidade com o outro, principalmente no tocante ao que se dispõe a transmitir a ele. Tal processo implica uma dimensão de ser presente junto a esse outro (Bioy, 2018), o que se afigura como uma forma de influência de grande valia na relação terapêutica quanto à experiência temporal vivida pelo sujeito. Isso porque o viver o presente, típico da primeiridade, consiste num convite para uma dimensão diáfana e potencial que, embora não se configure como concreta, é amplamente imbuída da capacidade de criação (Neubern, 2016). É nesse presente que o setting hipnótico pode favorecer a transformação de relações com o problema, de narrativas calcadas em eventos trágicos do passado e ausência 
de futuro, como trazido por Marcus, de modo a reconectar o sujeito a outros processos semióticos de seu universo. É também a partir desse presente que o terapeuta pode adentrar, via hipnose, o mundo desse sujeito e lá permanecer como um signo que evoque e impulsione a mudança. Em suma, é por meio desse presente que o sujeito pode se tornar protagonista e se apropriar de suas transformações, retomando autonomia diante de importantes momentos de sua vida paralisados pelas dores crônicas.

A dimensão temporal aqui destacada traz à tona a forte associação presente em várias propostas terapêuticas entre critérios externos e rapidez de resposta. Seja nos serviços oferecidos em muitas instituiçóes, seja nos adeptos da chamada hipnose rápida (Bioy, 2018), a pressa na obtenção de respostas, mesmo que por vezes justificável, costuma pautar o tratamento em torno de signos pertinentes para análises institucionais e técnicas, mas muito distantes das realidades vividas pelo sujeito. Sua produção simbólica, imaginária e emocional, envolvendo sobretudo sua autonomia, comumente não coincide com tais parâmetros e, como Marcus chegou até a afirmar, caso não sejam devidamente contempladas, favorecem um processo superficial que pouco impacta seu mundo. Logo, sem a inclusão do sujeito, não se torna possível responder à incômoda questão na qual se pergunta a quem o tratamento realmente serve (Erickson, 1985).

Nessa mesma linha de reflexão, de um ponto de vista técnico, a configuração da experiência de dor em dois grandes sistemas (autoimagem e esquema corporal) traz uma importante questão para a clínica hipnótica das dores crônicas (Neubern, 2016). Isso porque a inclusão do sujeito no processo hipnótico, como ser concreto e conceito teórico, não deve reduzir as intervenções técnicas ao plano simbólico, uma vez que existem também processos energéticos, vitais e reativos que ocupam um papel de grande influência nas configurações das dores crônicas. Disso resulta que uma leitura pertinente de semelhantes produções semióticas pode facilitar o processo terapêutico e evitar equívocos instrumentalistas, muito comuns nas perspectivas médicas, e antropomórficos, muito comuns entre psicólogos, que consiste numa espécie de simbolização intencional atribuída às dores de uma pessoa. Esse misto lamentável de psicossomática com autoajuda, por vezes, agrava o sofrimento de sujeitos como Marcus, pois, segundo tais narrativas, se essas pessoas teriam sido capazes de "produzir" aquela dor, deveriam ser capazes também de desfazê-la.

Numa ótica de iconicidade, no entanto, o tornar-se presente junto ao outro implica o tipo de espelhamento que se oferece a ele. Nesse sentido, ser consciente dessa transmissão vai além de conceber a iconicidade nas relações entre as metáforas e símbolos com a autoimagem do sujeito, e os diagramas e índices com seu esquema corporal (Neubern, 2016), pois essa relação não deve jamais 
ser artificial: ela deve ser tanto pertinente à produção semiótica do sujeito como ser ainda subjetivada pelo próprio terapeuta, de maneira que este encontre, em seu próprio mundo, a produção semiótica para formulá-las. É por tal razão que os sentimentos têm um papel importante não apenas nas palavras escolhidas, mas principalmente na dramaticidade (Schechner, 2013) que envolvem sua transmissão ao outro (Roustang, 2015), que comumente se faz acompanhar, no terapeuta, na construção de papéis específicos (Neubern, 2016). 


\section{REFERÊNCIAS}

Bioy, A. (2018). "O pequeno teatro da hipnose": uma leitura clínica do funcionamento hipnótico. In M. Neubern (Org.), Clínicas do transe: etnopsicologia, hipnose e espiritualidade no Brasil. (pp. 49-68). Curitiba: Juruá.

Breton, D. (2010). Anthropologie de la douleur. Paris: Métailié.

Colapietro, V. (1989). Peirce's approach to the self. New York: Suny.

Erickson, M. (1985). An introduction to the study and application of hypnosis in pain control. In M. Erickson (Org.), Healing in hypnosis. (pp. 217-277). New York: Irvington.

Gallagher, S., \& Zahavi, D. (2008). The phenomenological mind. New York: Routledge.

Hiraga, M. (2015). Iconicity: east meets west. Amsterdan: John Benjamins.

Jappy, T. (2013). Introduction to peircean visual semiotics. New York: Bloomsbury.

Jensen, M., \& Patterson, D. (2014). Hypnotic approaches for chronic pain management. American Psychologist, 2, 167-177.

Melchior, T. (1998). Créer le réel. Paris: Seuil.

Minkowski, E. (2005). Le temps vécu. Paris: Flammarion.

Morin, E. (2005). La méthode VI. L'Éthique. Paris: Seuil.

Neubern, M. (2014). Hipnose como proposta psicoterápica para pessoas com dores crônicas. Psicologia Argumento, 32, 159-169.

Neubern, M. (2016). Iconicidade e complexidade na comunicação hipnótica. Psicologia: Teoria e Pesquisa, 32 (n. esp.), 1-9.

Neubern, M. (2017). Contribuições da hipnose para a pesquisa qualitativa. Psico-USF, 22(2), 361-370.

Neubern, M. (2018). Clínicas do transe: etnopsicologia, hipnose e espiritualidade no Brasil. Curitiba: Juruá.

Nöth, W. (2015). The paradigms of iconicity in language and literature. In M. Hiraga (Org.), Iconicity: east meets west. (pp. 13-34). Amsterdan: John Benjamins. 
Peirce, C. (1998). The essential Peirce. Indianapolis: Indiana University Press.

Polejack, L., Vaz, A., Gomes, P., \& Wichrowski, V. (2015). Psicologia e politicas públicas na saúde. Experiências, reflexōes, interfaces e desafios. Porto Alegre: Rede Unida.

Roustang, F. (2015). Jamais contre, d'abord. La présence d'un corps. Paris: Odile Jacob.

Santaella, L. (2009). Matrizes da linguagem e do pensamento: sonora, visual, verbal. São Paulo: FAPESP, Iluminuras.

Schechner, R. (2013). Performance studies: an introduction. London: Routledge.

Schore, A. (2016). Affect regulation and the origin of the self. New York: Routledge.

Segato, R. (2005). Santos e daimones: o politeísmo afro-brasileiro e a tradição arquetipal. Brasília: Ed. UnB.

Zeig, J. (2014). The induction of hypnosis. Phoenix: Milton Erickson Foundation Press. 